\title{
Comparative Evaluation of the Apical Sealing Ability of Two Root Canal Sealers Using the Two Different Placement Techniques: An In Vitro Study
}

\author{
S Pallavi ${ }^{1}$, A Devadathan $^{2}$, Baby James $^{3}$, Jose Jacob $^{4}$, Manuja Nair ${ }^{5}$, NJ Nagaraj ${ }^{6}$
}

\begin{abstract}
Aim: To compare and evaluate the effect of two different sealer placement techniques on the apical sealing ability of MTA Fillapex and AH Plus root canal sealers.

Materials and methods: Study was performed on 40 extracted human single-rooted permanent teeth, which were decoronated and the root canals were instrumented. The specimens were randomly divided into four groups and obturated using single-cone technique. Group IA: Using AH Plus sealer; placed using master gutta percha (GP) cone, group IB: Using AH Plus sealer; placed using size 30 lentulospiral, group IIA: Using MTA Fillapex; placed using master GP cone, and group IIB: Using MTA Fillapex; placed using size 30 lentulospiral. Microleakage was evaluated using dye penetration method. Teeth were split longitudinally and then horizontal markings were made at 1.5, 4, and $6 \mathrm{~mm}$ from the apex. Dye penetration evaluation was performed under stereomicroscope (4× magnification) and statistically evaluated.

Results: The lowest microleakage values were obtained with group IIB (MTA Fillapex placed using lentulospiral) and the highest with group IA (AH Plus placed using mastercone).

Conclusion:Within the limitations of the study, MTA Fillapex sealer placed using lentulospiral achieved highest apical seal among the experimental groups. Though leakage cannot be totally eliminated from the fate of a root canal treated teeth, the type of root canal sealer and its placement plays a major role in the success of an endodontic treatment.
\end{abstract}

Keywords: AH Plus sealer, Microleakage, MTA fillapex, Root canal sealer.

Conservative Dentistry and Endodontic Journal (2020): 10.5005/jp-journals-10048-0059

\section{INTRODUCTION}

The primary objective of root canal obturation was to eradicate all routes of leakage from the oral cavity or periradicular tissues into the root canal system. ${ }^{1}$ An ideal endodontic sealer should flow along the entire canal wall surface, fill all the voids and gaps between the root filling material and dentin, and adhere to both dentin and gutta percha (GP). AH Plus, an epoxy-bis-phenol resin-based sealer, has been used as the gold standard material. ${ }^{2}$ It adheres to root dentin and has better penetration into the microirregularities, which increases the mechanical interlocking between sealer and root dentin. ${ }^{3}$

MTA-based endodontic sealers exhibit excellent biocompatibility, bioactivity, and osteoconductivity. ${ }^{4-6}$ MTA Fillapex has been recently developed in an attempt to combine the biological and sealing properties of MTA cements with the physicochemical properties required by a root sealer. On the one hand, an inadequate sealer coating may result in voids and permit bacterial microleakage which leads to endodontic failure. ${ }^{7}$ On the other hand, excess placement of the sealer can result in its extrusion beyond the apical foramen which can prevent or delay healing. ${ }^{8}$

Application of an endodontic sealer may be optimized using an efficient sealer placement technique. Accepted means of sealer placement include the use of endodontic files or reamers, lentulospirals, GP cones, ultrasonic files, and counter-clockwise motion of rotary systems. ${ }^{9}$ At present, there is no evidence to suggest that one method is better and reliable than the others.

In the present study, we compared the efficiency of two most commonly used placement techniques using mastercone and lentulospiral. Very few studies have been performed to evaluate \begin{tabular}{l}
\hline${ }^{1-5}$ Department of Conservative Dentistry and Endodontics, Pushpagiri \\
College of Dental Sciences, Thiruvalla, Kerala, India \\
${ }^{6}$ Department of Conservative Dentistry and Endodontics, SRM Dental \\
College and Hospital, Chennai, Tamil Nadu, India \\
Corresponding Author: S Pallavi, Department of Conservative \\
Dentistry and Endodontics, Pushpagiri College of Dental Sciences, \\
Thiruvalla, Kerala, India, Phone: +91 9400763434, e-mail: itspalluhere@ \\
gmail.com \\
How to cite this article: Pallavi S, Devadathan A, James B, et al. \\
Comparative Evaluation of the Apical Sealing Ability of Two Root Canal \\
Sealers Using the Two Different Placement Techniques: An In Vitro \\
Study. Cons Dent Endod J 2020;5(1):11-14. \\
Source of support: Nil \\
Conflict of interest: None
\end{tabular}

the efficacy of different methods of sealer placement and activation effectively. Hence, the aim of this study was to compare and evaluate the effect of two different sealer placement techniques on the apical sealing ability of MTA Fillapex and AH Plus root canal sealers.

\section{Materials and Methods}

Forty freshly extracted single-rooted mature human premolar teeth with fully formed apices, straight roots and without root caries, resorption or fracture, were selected for the study. Teeth were placed in $2.5 \%$ sodium hypochlorite $(\mathrm{NaOCl})$ (Prime Dental) for 2 hours and stored in normal saline until use. The teeth were 


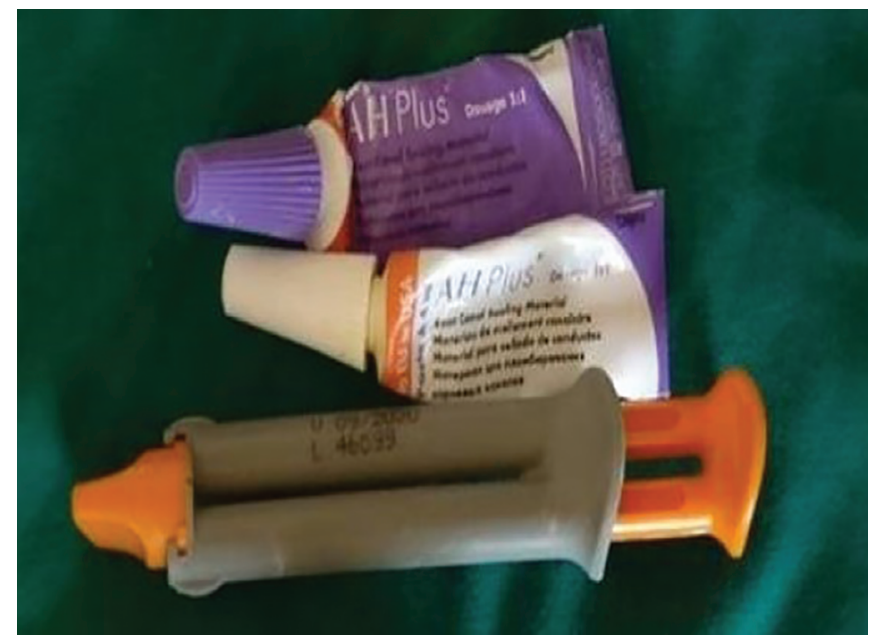

Fig. 1: AH Plus and MTA Fillapex sealers
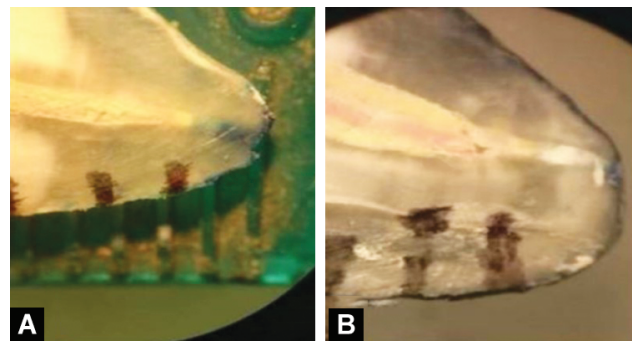

Figs 3A to D: Representative images of dye penetration from the four study groups

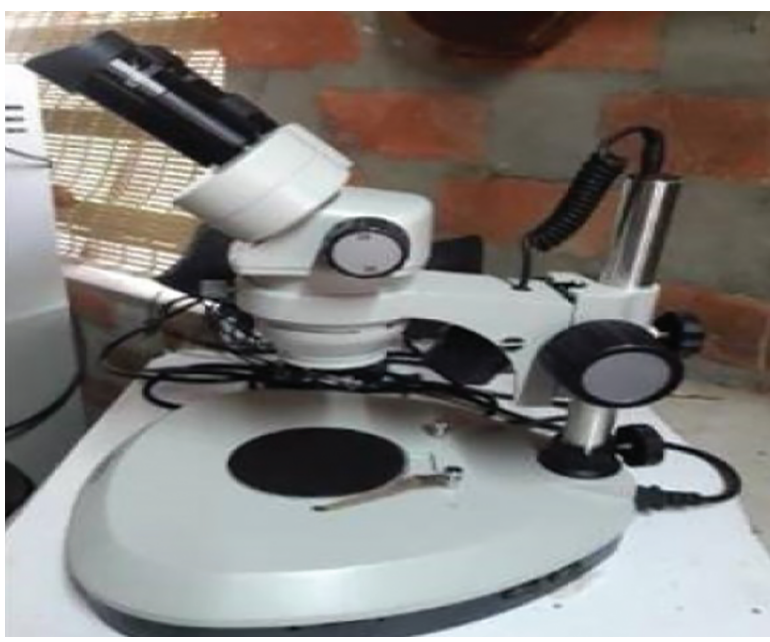

Fig. 2: Stereomicroscope
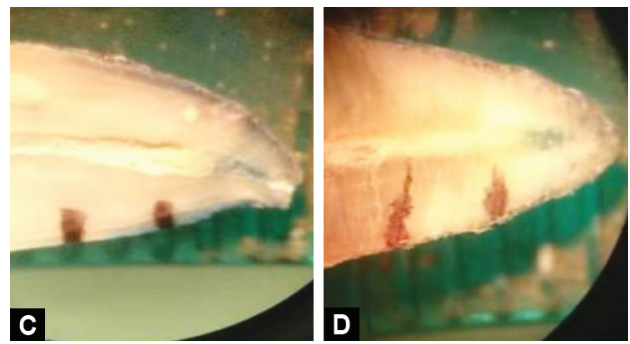

sectioned so as to obtain a standardized root length of $12 \mathrm{~mm}$ using a diamond saw under coolant. Working length was then determined using 15 size $\mathrm{K}$ file (Mani Inc.) extending just beyond the apical foramen and by subtracting $1 \mathrm{~mm}$ from the length of the file. Biomechanical preparation was performed using ProTaper Gold endodontic files (Dentsply Maillefer) in a sequential manner from S1 to F3. Canals were irrigated in-between files with $2 \mathrm{~mL}$ of $3 \% \mathrm{NaOCl}$ and normal saline and were dried using sterile paper points. Specimens were then randomly divided into 2 groups of 20 samples each (Fig. 1).

Group I: Obturation performed with F3 ProTaper GP cone and AH Plus sealer (Dentsply Maillefer).

Group II: Obturation performed with F3ProTaper GP cone and MTA Fillapex (Angelus Odontologicas).

\section{Sealer Placement Techniques}

Each group was further divided into 2 subgroups of 10 samples each on the basis of sealer placement technique.

- Subgroup A: The master GP cone was used to coat the canal walls with endodontic sealer till the working length.

- Subgroup B: Root canal sealer coated on size 30 lentulospiral (Mani Inc.) that would not bind in the prepared canal, rotated at the speed of $300 \mathrm{rpm}$ keeping the instrument $2 \mathrm{~mm}$ from apex for 20 seconds.

After sealer placement, single-cone obturation technique was performed using ProTaper F3 GP cone and were compacted $1 \mathrm{~mm}$ from the canal orifice. The access was sealed with type II glass ionomer cement and the specimens were stored in incubator at $100 \%$ air humidity for 24 hours. The surfaces of samples were dried
Table 1: Saunder's scoring criteria for apical leakage

\begin{tabular}{ll}
\hline Degree of leakage & Depth of penetration \\
\hline 0 & No leakage detected \\
1 & $<1 \mathrm{~mm}$ \\
2 & $1-1.5 \mathrm{~mm}$ \\
3 & $>1.5 \mathrm{~mm}$ \\
\hline
\end{tabular}

and two layers of colored nail varnish were applied on all surfaces of the teeth except for $2 \mathrm{~mm}$ from the apex.

\section{Dye Penetration}

The varnish applied roots were then suspended in freshly prepared $1 \%$ methylene blue dye for 48 hours. For this duration, the specimens were stored in incubator at $37^{\circ} \mathrm{C}$. Following this period, the roots were rinsed for 15 minutes under running tap water and dried.

\section{Preparation of Specimens for Microleakage Evaluation}

Specimens were split longitudinally parallel to the long axis with a diamond disc using a water coolant and the markings were made at $1.5,4$, and $6 \mathrm{~mm}$ from the apex. Depth of the dye penetration was examined under stereomicroscope (Fig. 2) at $4 \times$ magnification using millimeter scale with a resolution of $0.5 \mathrm{~mm}$ (Fig. 3). The depth of dye penetration was evaluated using scoring criteria given by Saunders et al. ${ }^{10}$ (Table 1).

\section{Results}

Using one-way analysis of variance (ANOVA), it was revealed that there was a statistically significant difference between the groups 
Table 2: Apical leakage scores for the study groups using Saunder's criteria

\begin{tabular}{|c|c|c|c|c|c|c|}
\hline \multirow[b]{2}{*}{ Groups } & \multirow[b]{2}{*}{ Description } & \multirow[b]{2}{*}{ No. of specimens } & \multicolumn{4}{|c|}{ Apical leakage score } \\
\hline & & & 0 (no leakage) & $1(<1 \mathrm{~mm})$ & $2(1-1.5 \mathrm{~mm})$ & $3(>1.5 \mathrm{~mm})$ \\
\hline IA & $\begin{array}{l}\text { AH Plus sealer; placed using master } \\
\text { GP cone }\end{array}$ & 10 & 0 & 2 & 4 & 4 \\
\hline IB & $\begin{array}{l}\text { AH Plus sealer; placed using } \\
\text { lentulospiral }\end{array}$ & 10 & 0 & 3 & 3 & 4 \\
\hline$\| \mathrm{A}$ & $\begin{array}{l}\text { MTA Fillapex; placed using master GP } \\
\text { cone }\end{array}$ & 10 & 2 & 2 & 5 & 1 \\
\hline IIB & $\begin{array}{l}\text { MTA Fillapex; placed using } \\
\text { lentulospiral }\end{array}$ & 10 & 3 & 3 & 4 & 0 \\
\hline
\end{tabular}

Table 3: Mean and standard deviation for dye penetration

\begin{tabular}{llllll}
\hline Groups & $N$ & Minimum value & Maximum value & Mean & Standard deviation \\
\hline Group IA & 10 & 0.5 & 3.00 & 1.600 & 0.876 \\
Group IB & 10 & 0.5 & 2.00 & 1.25 & 0.677 \\
Group IIA & 10 & 0 & 2.5 & 0.900 & 0.738 \\
Group IIB & 10 & 0 & 1.5 & 0.600 & 0.516 \\
\hline
\end{tabular}

( $p<0.001)$ for microleakage evaluation. There was a significant difference $(p<0.05)$ in mean microleakage evaluation values between group I (AH Plus) and group II (MTA Fillapex), tested using independent sample $t$ test. There was no significant difference between mean microleakage evaluation within the subgroup $A$ (placement using mastercone) and subgroup B (placement using lentulospiral) between groups I and II (Tables 2 and 3).

\section{Discussion}

The placement of sealer plays a significant role in ensuring apical seal. The degree of leakage could be reduced using a material that adapts well to the root canal walls. ${ }^{11,12}$ To evaluate the sealing ability of sealers, tracers like dyes, radioisotopes, bacteria, and their products, such as endotoxins, and other methodologies like fluid filtration and dye extraction techniques have been used.

One of the commonly applied methods to evaluate the sealing ability of different root filling materials and techniques was based on linear measurement of dye penetration. This method allows the production of sections showing leakage in contrasting colors to both tooth and restoration without the need for further chemical reaction or exposure to potentially hazardous radiation. ${ }^{13}$ Dyes like eosin, methylene blue, black India ink, Procion brilliant blue, etc., are used commonly. Methylene blue dye was used in this study as its molecular size was similar to bacterial by-products, such as butyric acid, which can leak out of infected root canals to irritate periapical tissues, also it was easy to use, $\mathrm{pH}$ manipulation, and availability add to it advantages. ${ }^{14,15}$

In the present study, root canals were prepared using ProTaper rotary files followed by single-cone obturation technique. The technique speeds the root canal filling while minimizes the pressure applied to the walls of root canals. The combination of single-cone and endodontic cement results in a uniform mass which prevents failures observed among multiple cones. ${ }^{16}$ The ProTaper system ensured proper fit of the master cone since the root canals were filled with the GP point size matching the size of the last instrument used. ${ }^{17}$ The present study evaluated the hemogeneous flow of sealer during stereomicroscopic evaluation, thus ensuring the obtained results were due to the sealers used and the placement techniques and not because of inadequacies in placement techniques.
Among the hurdles posed during studies of apical microleakage is the lack of standardization. Here, all the canals were prepared and obturated to the same size, conducted by single operator. Randomly assigning the teeth to each experimental group ensured in generating comparable intervention groups. The obtained values were evaluated using scoring criteria for apical microleakage as obtained from the study by Saunders et al. ${ }^{10}$ This aided in achieving standardized results.

The lowest microleakage values were achieved for MTA Fillapex placed using lentulospiral and highest for AH Plus sealer placed using master cone in the present study, which were in accordance with previous studies done by Vitti et al. and Nikhil et al., ${ }^{9,18}$ Using mastercone for sealer placement may cause non-uniform coating of the canal walls, resulting in inadequate sealing of the apical region. Using lentulospiral, the rapid insertion causes increased pseudoplasticity, increased flow, and significantly smaller quantity of voids. ${ }^{19}$

Said et al. in 2012 evaluated the effect of sealer placement using mastercone and lentulospiral on sealing ability of AH Plus and lateral condensation technique and concluded that lentulospiral group produced the highest value of microleakage and the master GP coating group had the smallest mean microleakage value. ${ }^{20}$ The present study, though, showed contradictory results; the reason for more microleakage in mastercone GP might be due to more sealer thickness with higher potential for void formation as compared to the lentulospiral technique.

MTA Fillapex achieved higher apical seal, which may be attributed to diffusion of sealer particles into the dentinal tubules to produce mechanical interlocking bonds. ${ }^{21}$ MTA forms calcium and hydroxyl ions which were important for the stimulation of hard tissue deposition. Sealability was also improved due to the presence of MTA because of possibility of setting expansion. Hydration of anhydrous mineral oxide compounds occurs to produce calcium silicate hydrate and calcium hydroxide phases, which produces expansion against its confining margins and improved the seal and minimize microleakage. Infiltration of the sealer's mineral content into the intertubular dentin resulting in establishment of mineral infiltration zone. ${ }^{22}$ Benezra et al. showed similar results and proved that MTA Fillapex exhibited a different microstructure at the interface than the bulk material. ${ }^{23}$ 
$\mathrm{AH}$ Plus sealer, though there is an increased mechanical interlocking between sealer and root dentin, earlier studies revealed that there is an inadequate bonding between the sealer and GP point, allowing fluid leakage at this interface. ${ }^{3,24}$ This could be one of the reasons group I (AH Plus) recorded a mean value significantly higher in vertical penetration of dye in comparison with MTA Fillapex.

Limitations of the present study includes the fact that it is an in vitro study conducted using a small sample size of 40 teeth. The results could have been more defined using more study samples. Also, dye penetration method was used to evaluate microleakage. Further studies have to be performed using sophisticated and more precise evaluation techniques to validate the present findings.

\section{Conclusion}

Within the limitations of the study, MTA Fillapex sealer placed using lentulospiral achieved highest apical seal among the experimental groups. Though leakage cannot be totally eliminated from the fate of a root canal-treated teeth, the type of root canal sealer and its placement plays a major role in the success of an endodontic treatment.

\section{References}

1. Gutmann JL, Kuttler S, Niemczyk SP. Root canal obturation: An update. Academy of Dental Therapeutics and Stomatology, a division of PennWel. 2010.

2. Zhou HM, Shen $Y$, Zheng $W$, et al. Physical properties of 5 root canal sealers. J Endod 2013;39(10):1281-1286. DOI: 10.1016/j. joen.2013.06.012.

3. Pawar SS, Pujar MA, Makandar SD. Evaluation of the apical sealing ability of bioceramic sealer, AH plus \& epiphany: an in vitro study. J Conservat Dent: JCD 2014;17(6):579. DOI: 10.4103/0972-0707.144609.

4. Torabinejad M, Parirokh M. Mineral trioxide aggregate: a comprehensive literature review-part II: leakage and biocompatibility investigations. J Endod 2010;36(2):190-202. DOI: 10.1016/j.joen.2009.09.010.

5. Kossev D, Stefanov V. Ceramics-based sealers as new alternative to currently used endodontic sealers. Roots 2009;1:42-48.

6. Ken K. A review of bioceramic technology in endodontics. Roots 2012;4:6-12.

7. Lin LM, Skriber JE, Gaengler P. Factors associated with endodontic treatment failures. J Endod 1992;18(12):625-627. DOI: 10.1016/S00992399(06)81335-X.

8. Hoen MM, Labounty GL, Keller DL. Ultrasonic endodontic sealer placement. J Endod 1988;14(4):169-174. DOI: 10.1016/S00992399(88)80257-7.

9. Nikhil V, Bansal P, Sawani S. Effect of technique of sealer agitation on percentage and depth of MTA Fillapex sealer penetration: a comparative in-vitro study. J Conservat Dent: JCD 2015;18(2):119. DOI: 10.4103/0972-0707.153073.

10. Saunders EM, Saunders WP, Rashid MY. The effect of post space preparation on the apical seal of root fillings using chemically adhesive materials. Int Endod J 1991;24(2):51-57. DOI: 10.1111/j.13652591.1991.tb00807.x.

11. Ørstavik D. Materials used for root canal obturation: technical, biological and clinical testing. Endod Topics 2005;12(1):25-38. DOI: 10.1111/j.1601-1546.2005.00197.x.

12. Bernardes RA, de Amorim Campelo A, Junior DSS, et al. Evaluation of the flow rate of 3 endodontic sealers: Sealer 26, AH plus and MTA obtura. Oral Surg Oral Med Oral Pathol Oral Radiol Endod 2010;109(1):e47-e49. DOI: 10.1016/j.tripleo.2009.08.038.

13. Taylor MJ, Lynch E. Microleakage. J Dent 1992;20(1):3-10. DOI: 10.1016/0300-5712(92)90002-t.

14. Veríssimo DM, do Vale MS. Methodologies for assessment of apical and coronal leakage of endodontic filling materials: a critical review. J Oral Sci 2006;48(3):93-98. DOI: 10.2334/josnusd.48.93.

15. Ahlberg KM, Assavanop P, Tay WM. A comparison of the apical dye penetration patterns shown by methylene blue and India ink in root-filled teeth. Int Endod J 1995;28(1):30-34. DOI: 10.1111/j.13652591.1995.tb00153.x.

16. Pereira AC, Nishiyama CK, de Castro Pinto L. Single-cone obturation technique: a literature review. RSBO revista sul-brasileira de. Odontologia 2012;9(4):442-447.

17. Inan U, Aydin C, Tunca YM, et al. In vitro evaluation of matched-taper single-cone obturation with a fluid filtration method. J Can Dent Assoc 2009;75(2):123.

18. Vitti RP, Prati C, Silva EJ, et al. Physical properties of MTA Fillapex sealer. J Endod 2013;39(7):915-918. DOI: 10.1016/j.joen.2013. 04.015 .

19. Guinesi AS, Faria G, Tanomaru-Filho M, et al. Influence of sealer placement technique on the quality of root canal filling by lateral compaction or single cone. Braz Dent J 2014;25(2):117-122. DOI: 10.1590/0103-6440201302370.

20. Said HM, Bakar WZ, Farea M, et al. The effect of different sealer placement techniques on sealing ability: an in vitro study. J Conservat Dent: JCD 2012;15(3):257. DOI: 10.4103/0972-0707.97952.

21. Ahuja L, Jasuja P, Verma KG, et al. A comparative evaluation of sealing ability of new MTA based sealers with conventional resin based sealer: an in-vitro study. J Clin Diagnos Res 2016;10(7):ZC76. DOI: 10.7860/ JCDR/2016/18909.8194.

22. Al-Haddad A, Ab Aziz C, Zeti A. Bioceramic-based root canal sealers: a review. Int J Biomater 2016;2016:9753210. DOI: 10.1155/2016/ 9753210.

23. Benezra MK, Wismayer PS, Camilleri J. Interfacial characteristics and cytocompatibility of hydraulic sealer cements. J Endod 2018;44(6):1007-1017. DOI: 10.1016/j.joen.2017.11.011.

24. Kim YK, Grandini S, Ames JM, et al. Critical review on methacrylate resin-based root canal sealers. J Endod 2010;36(3):383-399. DOI: 10.1016/j.joen.2009.10.023. 